\title{
ANALISIS KESTABILAN SYSTEM TENAGA LISTRIK PADA GEDUNG KAWASAN INDUSTRI MAKASSAR (KIMA)
}

\author{
Yusri Ambabunga, ST., MT \\ UNIVERSITAS KRISTEN INDONESIA (UKI) TORAJA \\ Email : ambabungayusri@gmail.com
}

\begin{abstract}
ABSTRAK
Penelitian ini bertujuan untuk mengetahui nilai besarnya sudut pemutus daya kritis dalam menentukan Kestabilan Sistem Tenaga Listrik pada keadaan peralihan (transient) serta mengetahui nilai besarnya waktu pemutus kritis dalam menentukan Kestabilan Sistem Tenaga Listrik pada keadaan peralihan (transient ). Lamanya waktu pemutus kritis untuk menentukan Kestabilan Sistem Tenaga Listrik dalam keadaan peralihan (transient) dari kondisi beban nol ke kondisi beban penuh begitupun sebaliknya berada pada batasan 0,26 detik sampai 0,5 detik. Sehingga nantinya di dalam penelitian ini dapat memberikan suatu informasi yang bermanfaat dalam melihat Sistem Tenaga Listrik ini secara menyeluruh terutama kerja peralatan Sistem Tenaga Listrik dimulai dari Pusat Pembangkit, Saluran Transmisi, Pusat beban baik beban primer maupun beban sekunder..
\end{abstract}

\section{PENDAHULUAN}

\subsection{Latar Belakang Masalah}

Listrik adalah bentuk energi sekunder yang paling praktis penggunaannya oleh manusia, dimana listrik dihasilkan dari proses konversi energi sumber primer seperti batubara, minyak bumi, gas, panas bumi, potensial air dan energi angin. Kebutuhan listrik di masyarakat semakin meningkat seiring dengan meningkatnya pemanfaatan tenaga listrik pada peralatan - peralatan rumah tangga, kantor dan sebagainya. Sumber tenaga listrik yang baik adalah sistem tenaga yang dapat melayani beban secara kontinu dengan frekwensi dan tegangan yang konstan. 
Fluktuasi tegangan dan frekwensi yang terjadi harus berada pada batas toleransi yang diizinkan agar peralatan listrik konsumen dapat bekerja dengan baik dan aman. Oleh karena itu diperlukan suatu analisis sistem tenaga listrik untuk menentukan apakah sistem tersebut stabil atau tidak. Sehingga di dalam penelitian ini penulis mengambil judul Analisis Kestabilan Sistem Tenaga Listrik Pada Gedung Kawasan Industri Makassar (KIMA).

\subsection{Rumusan Masalah}

Berdasarkan latar belakang di atas, rumusan masalah yang dapat dikemukakan dalam studi ini adalah :

a. Berapa besarnya sudut pemutus kritis ( Critical Clearing Angle ) untuk menentukan kestabilan Sistem Tenaga Listrik pada Gedung Kawasan Industri Makassar pada kondisi transient ( peralihan ).

b. Berapa lamanya waktu pemutus kritis ( Critical Clearing Time) untuk menentukan kestabilan Sistem Tenaga Listrik pada Gedung Kawasan Industri Makassar pada kondisi transient ( peralihan )

\subsection{Batasan Masalah}

Berdasarkan rumusan masalah diatas, maka batasan masalah yang dapat dikemukakan dalam studi ini adalah :

a. Menentukan sudut pemutus kritis ( Critical Clearing Angle) untuk menentukan kestabilan Sistem Tenaga Listrik pada Gedung Rektorat Atmajaya Makassar pada kondisi transient ( peralihan )

b. Menentukan waktu pemutus kritis ( Critical Clearing Time) untuk menentukan kestabilan Sistem Tenaga Listrik pada Gedung Rektorat Atmajaya Makassar pada kondisi transient ( peralihan )

\subsection{Tujuan Penelitian}

Adapun tujuan penelitian ini adalah :

a. Untuk mengetahui kondisi Sistem Jaringan Listrik pada Gedung Kawasan Industri Makassar apabila terjadi gangguan 3 phasa maupun 1 phasa pada 
Sistem Tenaga Listrik yang terbentuk dan terpasang pada Sistem Gedung Kawasan Industri Makassar (KIMA)

b. Untuk mengetahui perubahan karakteristik peralatan peralatan listrik yang terpasang pada Gedung Kawasan Industri Makassar apabila terjadi fluktuasi frekwensi yang berdampak pada fluktuasi tegangan listrik pada sistem tenaga listrik secara menyeluruh.

\section{KAJIAN PUSTAKA}

\section{1 . Stabilitas Dalam Sistem Tenaga Listrik}

Dalam keadaan operasi yang stabil dari sistem tenaga listrik, terdapat keseimbangan antara daya input mekanis pada prime mover dengan daya output listrik (beban listrik) pada sistem tenaga listrik. Dalam keadaan ini semua generator berputar pada kecepatan sinkron. Hal ini terjadi bila setiap kenaikan dan penurunan beban harus diikuti dengan perubahan daya input mekanik pada prime mover dari generator generator tersebut. Bila daya input mekanik tidak cepat mengikuti dengan perubahan beban dan rugi rugi sistem maka kecepatan rotor generator ( Frekwensi System ) dan tegangan akan menyimpang dari keadaan normal terutama jika terjadi gangguan, maka sesaat terjadi perbedaan yang besar antara daya input mekanik dan daya output listrik dari generator . Kelebihan daya mekanik terhadap daya listrik mengakibatkan percepatan pada putaran rotor generator atau sebaliknya, bila gangguan tersebut tidak dihilangkan segera maka percepatan (acceleration) dan perlambatan ( decceleration ) putaran rotor generator akan mengakibatkan hilangnya sinkronisasi dalam sistem tenaga listrik. Stabilitas sistem tenaga listrik adalah suatu kemampuan sistem tenaga listrik atau bagian komponennya untuk mempertahankan sinkronisasi dan keseimbangan dalam sistem.

\subsection{Dinamika Rotor Dan Persamaan Ayunan.}

Persamaan yang mengatur gerakan rotor suatu mesin serempak didasarkan pada prinsip dasar dinamika yang menyatakan bahwa momen putar percepatan (accelerating torque ) adalah hasil kali dari momen momen kelembaman ( momn 
of inersia ) rotor dan percepatan sudutnya. Momen putar mekanik dan momen putar elektris dianggap positif untuk generator serempak. Ini berarti bahwa adalah resultan momen putar poros yang mempunyai kecenderungan untuk mempercepat rotor dalam arah putaran yang positif. Untuk generator yang bekerja dalam keadaan tetap dan adalah sama, sedangkan momen putar sama dengan nol. Penggerak mulanya mungkin berupa turbin air atau turbin uap dan untuk masing masing turbin sudah ada model dengan bermacam macam tingkat kesulitan untuk melakukan pengaurh pada putaran rotor generator tersebut.

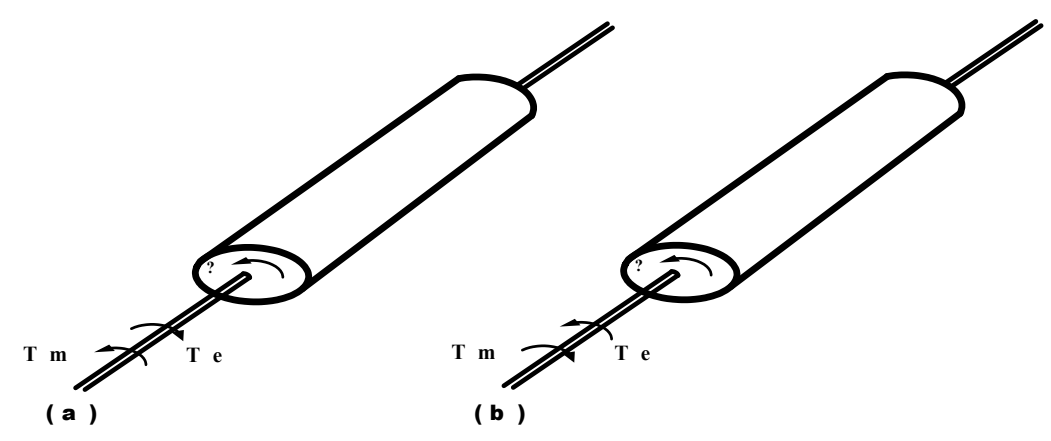

Gambar 2.2. Rotor mesin yang membandingkan arah perputaran serta momen putar mekanis dan elektris (Stevenson, 1996:352).

\section{METODOLOGI PENELITIAN}

\subsection{Waktu Dan Lokasi Penelitian}

Penelitian ini dilaksanakan selama 3 bulan mulai dari bulan September sampai dengan November 2017 pada Gedung Kawasan Industri Makassar (KIMA)

\subsection{Metode Pengumpulan Data.}

Untuk mendapatkan data yang diperlukan dalam penelitian ini maka metode yang digunakan adalah :

a. Penelitian Pustaka ( Library Research ) yaitu dengan membaca berbagai literatur yang relevan dengan masalah yang akan dibahas. 
b. Penelitian Lapangan ( Field Research ) yaitu dengan pengambilan data yang langsung dilakukan di lapangan berupa eksperimen.

c. Salah satu metode yang digunakan untuk menentukan kestabilan suatu sistem tenaga listrik apabila mengalami gangguan adalah metode kriteria sama luas. Walaupun metode ini tidak dapat dipergunakan untuk sistem multimesin namun sangatlah membantu untuk memahami faktor faktor dasar yang mempengaruhi stabilitas transient pada Gedung Kawasan Industri Makassar (KIMA).

\section{PEMBAHASAN DAN HASIL}

\subsection{Data}

Model sistem tenaga listrik 3 phasa pada Gedung Kawasan Industri Makassar (KIMA) terdiri dari dua buah mesin yang mana mesin 1 sebagai pembangkit daya (generator) dan mesin 2 dipasang pada bus Infinite, dua buah transformator (trafo) masing masing trafo 1 sebagai penaik tegangan (Step Up ) dan trafo 2 sebagai penurun tegangan ( Step Down ). Berikut dibawah ini akan diperlihatkan Single Line Diagram Sistem Tenaga Listrik 3 phasa secara sederhana pada Gedung Kawasan Industri Makassar (KIMA) :

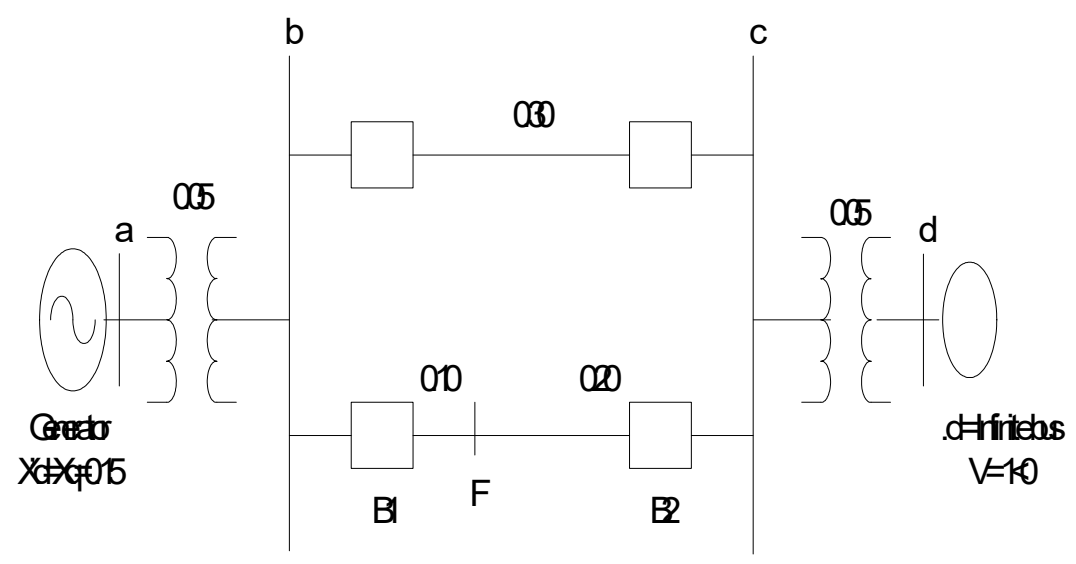

Gambar 4.1. Model system yang digunakan dalam studi stabilitas transient pada Gedung KIMA. 
Keterangan Gambar :

M1, M2 = Generator dan Infinite bus

$\mathrm{TR} 1, \mathrm{TR} 2=$ Transformator daya

B $1,2=$ Circuit Breaker

$\mathrm{F} \quad=$ Saluran yang mengalami gangguan

Tabel 4.1. Parameter-parameter penelitian

\begin{tabular}{|c|l|c|}
\hline No & Parameter-parameter & Reaktansi (X) dalam p.u. \\
\hline 1. & Reaktansi generator & $\mathrm{j} 0,15$ \\
2. & Reaktansi Trafo 1 & $\mathrm{j} 0,05$ \\
3. & Reaktansi Trafo 2 & $\mathrm{j} 0,05$ \\
4. & Reaktansi Saluran Transmisi 1 & $\mathrm{j} 0,30$ \\
5. & Reaktansi Saluran Transmisi 2 & $\mathrm{j} 0,30$ \\
6. & Tegangan referensi beban & $1,0 \angle 0^{\circ}$ \\
\hline
\end{tabular}

\subsection{Menghitung Reaktansi Saluran Transmisi Sebelum Terjadi Gangguan Di} Gedung KIMA

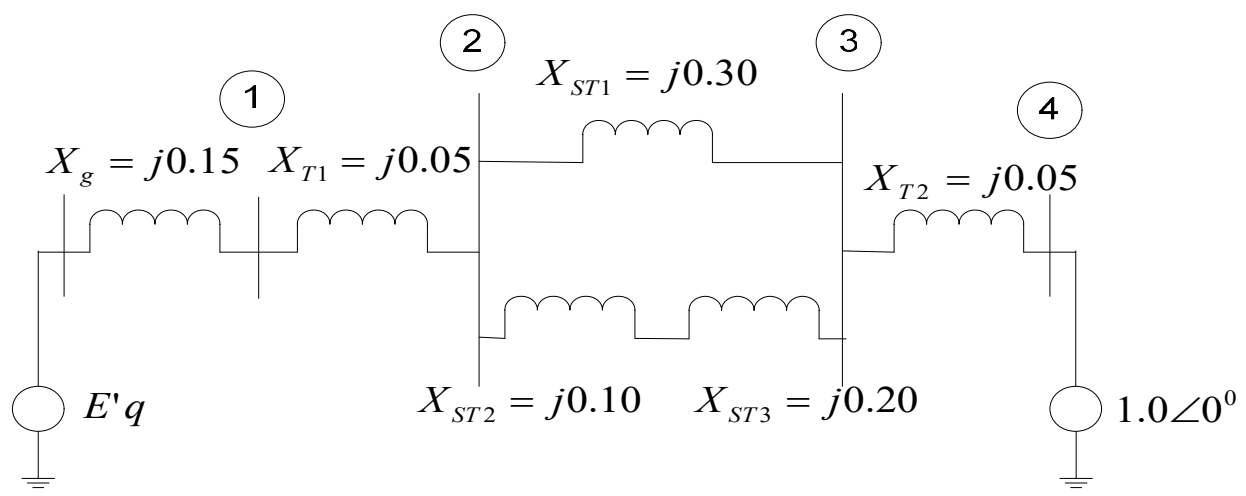

Gambar 4.2. Diagram reaktansi saluran sebelum terjadi gangguan di KIMA

$$
\begin{aligned}
j X & =X_{q}+X_{T 1}+\frac{\left(X_{S T 1}\right)\left(X_{S T 3}+X_{S T 2}\right)}{X_{S T 1}+X_{S T 3}+X_{S T 2}}+X_{T 2} \\
j X & =j 0,15+j 0,05+\frac{(j 0,30)(j 0,20+j 0,10)}{j 0,03+j 0,20+j 0,10}+j 0,05 \\
& =j 0,15+j 0,05+j 0,15 \\
& =j 0,35 p u
\end{aligned}
$$


4.3. Menghitung Reaktansi Saluran Saat Terjadi Gangguan Di Gedung KIMA

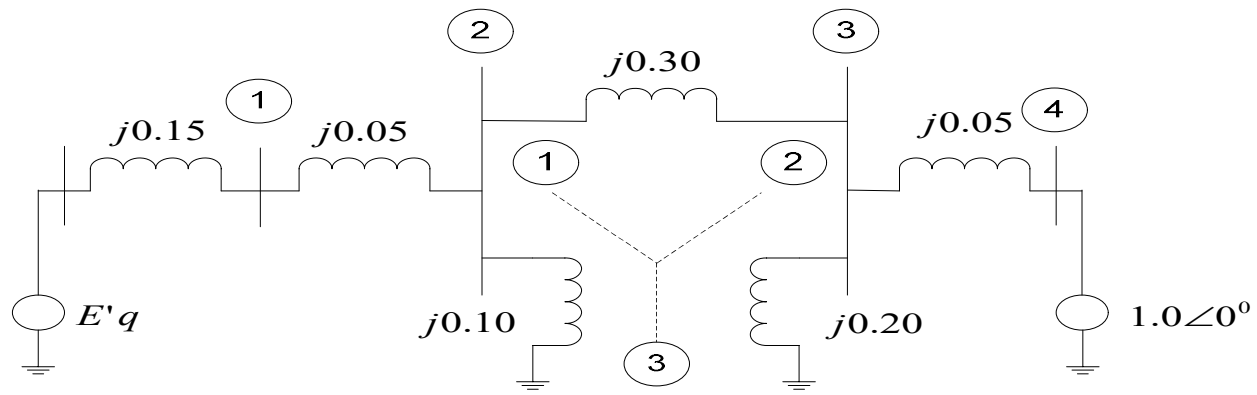

Gambar 4.3. Diagram reaktansi selama gangguan semua saluran ditanahkan dan dihubung Y untuk mencari impedansi pengganti pada Gedung KIMA Makassar.

$$
\begin{aligned}
Z_{1} & =\frac{\left(X_{S T 1}\right)\left(X_{S T 2}\right)}{X_{S T 1}+X_{S T 3}+X_{S T 2}} \\
Z_{1} & =\frac{(j 0,3)(j 0,1)}{j 0,3+j 0,2+j 0,1}=\frac{-0.03}{j 0,6}=j 0,05 p u \\
Z_{2} & =\frac{\left(X_{S T 1}\right)\left(X_{S T 3}\right)}{X_{S T 1}+X_{S T 3}+X_{S T 2}} \\
Z_{2} & =\frac{(j 0,3)(j 0,2)}{j 0,3+j 0,2+j 0,1}=\frac{-0.06}{j 0,6}=j 0,01 p u \\
Z_{3}= & \frac{\left(X_{S T 2}\right)\left(X_{S T 3}\right)}{X_{S T 1}+X_{S T 3}+X_{S T 2}}
\end{aligned}
$$

$$
Z_{3}=\frac{(j 0,1)(j 0,2)}{j 0,3+j 0,2+j 0,1}=\frac{-0,02}{j 0,6}=j 0,0333 p u
$$

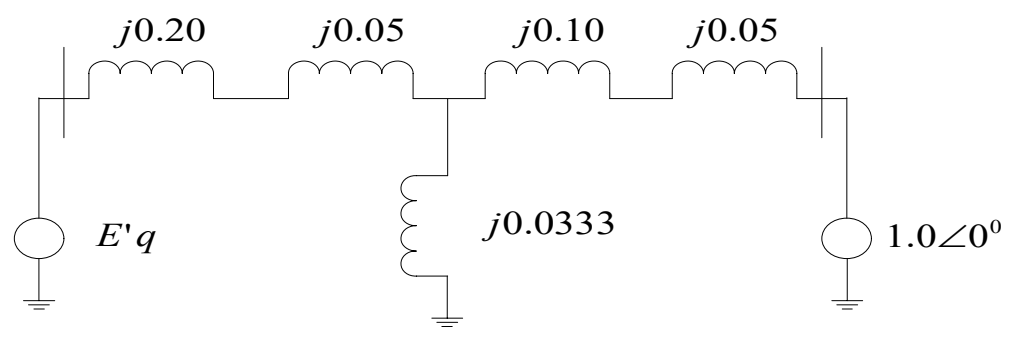

Gambar 4.4. Diagram reaktansi ketika saluran telah dihubung bintang ( Hubung 'Y ) 


$$
\begin{aligned}
\mathrm{jX} & =\frac{\left(X_{q}+X_{T 1}\right)\left(Z_{3}\right)+\left(X_{q}+X_{T 1}\right)\left(Z_{2}+X_{T 2}\right)+\left(Z_{2}+X_{T 2}\right)\left(Z_{3}\right)}{Z_{3}} \\
j X & =\frac{(j 0,25)(j 0,0333)+(j 0,25)(j 0,15)+(j 0,15)(j 0,0333)}{j 0,0333} \\
& =j 0,25+j 0,15+\frac{(j 0,25)(j 0,15)}{j 0,0333} \\
& =j 1,5261 p u
\end{aligned}
$$

\subsection{Menghitung Reaktansi Saluran Setelah Terjadi Gangguan Di Gedung} KIMA.

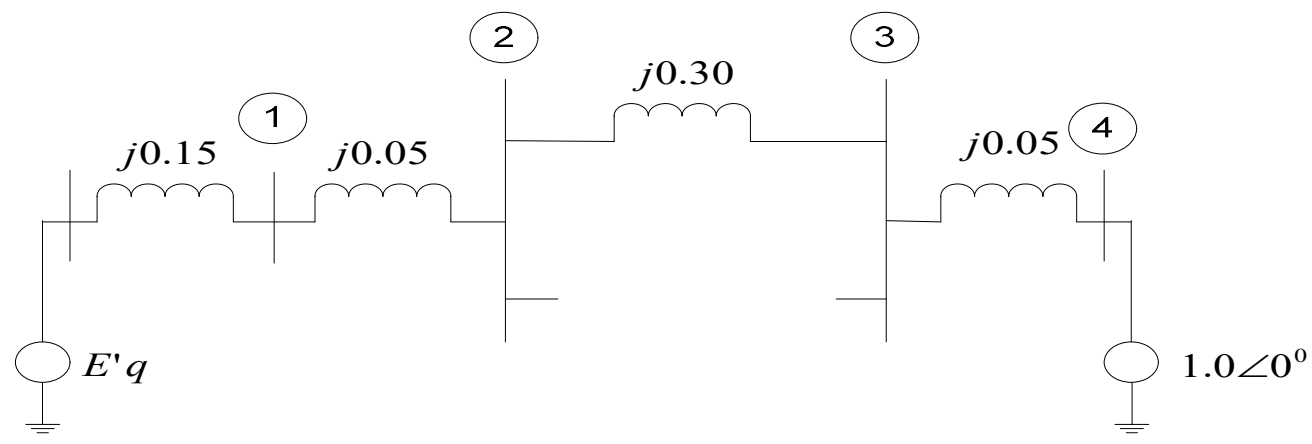

Gambar 4.6. Diagram reaktansi setelah terjadi gangguan B1 dan B2 terbuka

$$
\begin{aligned}
\mathrm{jX} & =\mathrm{X}_{\mathrm{q}}+\mathrm{X}_{11}+\mathrm{X}_{\mathrm{ST} 1}+\mathrm{X}_{\mathrm{T} 2} \\
& =\mathrm{j} 0,15+\mathrm{j} 0,05+\mathrm{j} 0,03+\mathrm{j} 0,05=\mathrm{j} 0,55 \mathrm{pu}
\end{aligned}
$$

\section{KESIMPULAN DAN SARAN}

\subsection{Kesimpulan}

Dengan menggunakan model sistem tenaga listrik yang terdiri dari sebuah mesin dan 1 bus infinite dengan saluran transmisi ganda dimana gannguan tiga fasa terjadi pada salah satu saluran maka dengan metode kriteria luas sama menggunakan matlab dapat disimpulkan :

1. Dari sistem tenaga listrik tersebut didapatkan nilai sudut kerja awal $20,3231^{0}$, sudut pemutus kritis $101,1263^{\circ}$, sudut ayunan maksimum $151,474^{0}$, dan waktu pemutusan kritis 0,25 detik. 
2. Bila breaker terbuka dengan sudut clearing (Clearing Angle) sama dengan atau kurang dari sudut kritis $\left(\delta_{p} \leq \delta_{k}\right)$ akan didapatkan kestabilan kembali dalam sistem tenaga listrik tersebut.

3. Bila breaker terbuka dengan sudut clearing (Clearing Angle) lebih besar dari sudut kritis $\left(\delta_{p}>\delta_{k}\right)$ tidak akan didapatkan kestabilan artinya sistem tenaga listrik tersebut mengalami gangguan total.

\subsection{Saran}

Dari hasil studi penelitian yang dilakukan disarankan menseting breaker terbuka dengan sudut clearing (Clearing Angle) lebih kecil atau sama dengan sudut kritis $\left(\delta_{p} \leq \delta_{k}\right)$ karena pada saat terjadi gangguan pada sistem tenaga listrik yang mendadak dan besar akan didapatkan kestabilan sistem kembali normal masih ada.

Diharapkan nantinya ada studi pengembangan lebih lanjut tentang masalah kestabilan sistem tenaga listrik pada mesin majemuk (multi mesin).

\section{DAFTAR PUSTAKA}

Cekdin, Cekmas. 2006. Sistem Tenaga Listrik. Yogyakarta: Penerbit Andi.

Darmawan, Agung. 2002. Studi Stabilitas Transient Sistem Tenaga Listrik Menggunakan Kriteria Luas Sama. Skripsi tidak diterbitkan. Surabaya: JPTE FT Unesa.

2006. Panduan Penulisan dan Penilaian Skripsi. Surabaya : Unesa University Press.

Gross, C.A. 1979. Power System Analysis. New York. John Wiley \& Sons.

Hanselman, D., dan B. Littlefield, 2000. Matlab Bahasa Komputasi Teknis. Yogyakarta : Penerbit Andi.

Sugiharto, Aris.2006. Pemrograman GUI dengan Matlab. Yogyakarta : Penerbit Andi.

Scheid, Francis. 1992. Analisis Numerik Teori dan Soal-Soal. Pantur Silaban $\mathrm{Ph} . \mathrm{D}$, Penterjemah. Jakarta: Erlangga. 
DYNAMIC SAINT

JDS, Jilid III no. 2, April 2018

Stevenson, W.D. 1996. Analisis Sistem Tenaga Listrik. Kamal Idris, Penterjemah. Jakarta: Erlangga.

Wrahatnolo, Tri. Diktat Mata Kuliah Analisa Sistem Tenaga Listrik II. Surabaya. 